\title{
Uniqueness Theorems for the Determination of a Coefficient in a Quasilinear Parabolic Equation
}

\section{S. DÜMAEL}

Für die’ quasilineare parabolische Gleichung $u_{t}=q(u) \Delta u$ werden zwei' Eindeutigkeitssätze für die Bestimmung des Koeffizienten $q(u)$ für den Fall, daß $q$ analytisch ist, und für den Spezialfall, daß $q$ linear von $u$ abhängt, bewiesen.

П̈ля нвазилинейного параболического уравненія $u_{t}=\cdot q(u) \Delta u$ доказываются теоремы единствениост для определени коэффициента $q(u)$ в случае, ногда $q$ пнляется аналити-

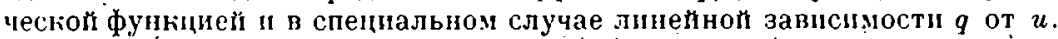

Two uniqueness theorems for the determination of the coefficient $q(u)$ in the quasilinear parabolic equation $u_{t}=q(u) \Delta u$ are proved for the case that $q$ is analytic and for the special case, that $q$ depends linearly on $u$.

\section{Introduction}

We consider the quasilinear parabolic equation

$$
u_{i}(x, t)=q(u(x, t)) \Delta u(x, t)
$$

with an initial condition and a boundary condition of the first kind. We assume that the unique solution $u$ of this problem is known at interior points of the domain and prove a uniqueness theorem for $q(u)$ for the case that $q$ is an analytic function of $u$ and for the special case that $q$ depends linearly on $u$.

The case $q=q(x)$ can be found in several papers (compare e.g. N. YA. Beznoshchenko [1], S. DüMmet, [4], A. L. Bukggerm and M. V. Klibaxov [2], C. D. Pagani [10], V. M. Isakov [7]). For the case $q=q(u)$ there are also several results (compare e.g. A. D. Iskexderov [8], N.V. Mozylev [9], P:Duchateau [3]). 'The mentioned authors assume that there is given additional information about $u$ on the boundary of the considered domain. $N$. V. MUzYLEv [9] and P. Duchateau ${ }^{-[3]}$ consider the one-dimensional case and the differential equation $u_{t}(x, t)=\left(q\left(u(x, t) u_{x}(x, t)\right)_{x}\right.$.

The equation (1:1) is closely related to the more general equation

$$
\text { , } u_{i}=\operatorname{div}\left(q(u)^{\prime} \operatorname{grad} u\right)=q(u) \Delta u+q^{\prime}(u) \operatorname{grad}^{2} u \text {. }
$$

For sufficiently small grad $u$ the equation (1.1) can be obtained from (1.2) by neglecting the last term in (1.2). An equation of the form (1.1) can also be obtained from (1.2) by a suitable transformation. But the theorems of this paper contain only results for (1.1) and not for (1.2). For the treatment of (1.2) further considerations are necessary.

We' use the following notations. $D$ is a bounded region of the $n$-dimensional Euclidean. space $\mathrm{R}^{n}(n=1,2, \ldots)$ with a sufficiently smooth boundary $\partial D, T$ a positive number, $Z_{T}=D \times(0, T), \Gamma_{T}=\partial D \times[0, T)$. By $\bar{M}$ we denote the closure of the set $M\left(M \subset \mathbf{R}^{n}\right.$ or $\left.M \subset \mathbf{R}^{n+1}\right)$. Points of the $\mathbf{R}^{n}$ are denoted by ${ }^{0} x=\left(x_{1}\right.$, $\left.x_{2}, \ldots, x_{n}\right)$ and $t$ is a real variable (time) with $0 \leqq t \leqq T$. We write $C(M)$ :for the 
set of all functions which are continuous in $M$. For points $P=(x, t)$ and $\bar{P}=(\bar{x}, \bar{l})$ we introduce the distance

$$
\dot{d}(\dot{P}, \bar{P})=\left(\|x-\bar{x}\|_{\mathbf{R}^{n}}^{2}+|t-\bar{\imath}|\right)^{1 / 2} .
$$

Using this distance we denote the space of all functions uniformly Hölder continuous with the exponent $\alpha$ in $Z_{T}$ by $\bar{C}_{a}\left(Z_{T}\right)$. By $\bar{C}_{2+a}\left(Z_{T}\right)$ we denote the space of all functions possessing uniformly Hölder continuous derivatives up to the order 2 with respect to $x_{i}(i=1,2, \ldots, n)$ and up to the order 1 with respect to $t$ in $Z_{T}$. For the precise definitions compare A. Friedman [5: p. 61].

Let the above-introduced boundary value problem be stated in the form

$$
\left.\begin{array}{ll}
u_{t}(x, t)=q(u(x, t)) \Delta u(x, t) & \text { in } Z_{T} \\
u(x, t)=\psi(x, t) & \text { on } \Gamma_{T} \\
u(x, 0)=\varphi(x) & \text { in } \bar{D}
\end{array}\right\} .
$$

Here $\psi$ and $\varphi$ are given functions satisfying the conditions

$$
\psi \in C\left(\bar{\Gamma}_{T}\right), \quad \varphi \in C(\bar{D}), \quad \varphi(x)=\psi(x, 0) \text { for } x \in \partial D .
$$

We define

$$
\begin{aligned}
v_{0} & =\min \left\{\min _{x \in \bar{D}} \varphi(x), \min _{(x, t) \in \bar{\Gamma}_{T}} \psi(x, t)\right\}, \\
v_{1} & =\max \left\{\max _{x \in \bar{D}} \varphi(x), \max _{(x, t) \in \bar{T}_{T}} \psi(x, t)\right\} .
\end{aligned}
$$

We assume that $v_{0}<v_{1}$ and that $q(u)$ is analytic in an interval $\left[v_{0}{ }^{*}, v_{1}{ }^{*}\right]$ with $v_{0}{ }^{*}<i_{0}<v_{1}<v_{1}^{*}$. Further let $q(u)>0$ for $u \in\left[v_{0}, v_{1}\right]$. In this case we say that $q$ is of the class $A$ or $q \in A$. Iet the function $u$ satisfy the conditions

$$
u \in C\left(\bar{Z}_{T}\right) \cap \bar{C}_{2+a}\left(Z_{T}\right), . \Delta u \in C\left(\bar{Z}_{T}\right) \text {. }
$$

- Further we assume that under the stated a'ssumptions for every $q \in A$ there is a unique solution $u=u(x, t, \dot{q})$ of the boundary value problem (1.3).

\section{A uniqueness theorem for the case that $q$ is analytic}

In this section we shall show that $q$ is uniquely determined if $u\left(x^{0}, t, q\right)=g(t)$ is known for a fixed $x^{0} \in D$ and for all $t \in[0, T]$, and if some other conditions are fulfilled.

Theorem 1:- Let $\varphi$ and $\psi$ be given functions satisfying (1.4) and $\varphi(x)=d$ on $\bar{D}$ for a constant d. We assume that $g$ is a function which is continucusly differentiable in $[0, T]$, and that there exists a positive number $t_{0}$ such that

$$
g^{\prime}(t)>0 \text { for all } t \in\left(0, t_{0}\right] \text {. }
$$

Let the function $u$ satisfy (1.6) and the condition

$$
u_{t}(x, t, q) \geqq 0 \text { for all }(x, t) \in Z_{T} \text { and } q \in A \text {. }
$$

Finally let $x^{0} \in D$. Then there is at most one $q \in A$ such that $u\left(x^{0}, t, q\right)=g(t)$ for all $t \in[0, T]$. 
Proof: We assunie that there are two functions $q_{1}, q_{2} \in A$ such that

$$
u\left(x^{0}, t, q_{1}\right)=u\left(x^{0}, t, q_{2}\right)=g(t) \text { for all } t \in[0, T] .
$$

For abbreviation we set $u_{i}(x, t) \doteq u\left(x, t, q_{i}\right)(i=1, \hat{2}), \tilde{u}=u_{1}-u_{2}, \tilde{q}=q_{1}-q_{2}$, and we obtain'

$$
\begin{aligned}
\partial \tilde{u} / \partial t & =q_{1}\left(u_{1}\right) \Delta u_{1}-q_{2}\left(u_{2}\right) \Delta u_{2} \\
& =q_{1}\left(u_{1}\right) \Delta \tilde{u}+\left[q_{1}\left(u_{1}\right)-q_{1}\left(u_{2}\right)\right] \Delta u_{2}+\tilde{q}\left(u_{2}\right) \Delta u_{2} .
\end{aligned}
$$

For.all $(x, t) \in \bar{Z}_{T}$ we define

$$
f(x, t)= \begin{cases}\frac{q_{1}\left(u_{1}(x, t)\right)-q_{1}\left(u_{2}(x, t)\right)}{u_{1}(x, t)-u_{2}(x, t)} & \text { if } u_{1}(x, t) \neq u_{2}(x, t), \\ q_{1}^{\prime}\left(u_{2}(x, t)\right), & \text { if } u_{1}(x, t)=u_{2}(x, t) .\end{cases}
$$

Then it follows that $f \in \bar{C}_{\alpha}\left(Z_{T}\right)$ and

$$
\frac{\partial \bar{u}}{\partial i}-q_{1}\left(u_{1}\right) \Delta \bar{u}-f \dot{u} u_{2} \bar{u}=q\left(u_{2}\right) \Delta l u_{2} \text { for all }(x, t) \in Z_{T}
$$

Further we have $\bar{u}(x, t)=0$ for all $(x, t) \in \Gamma_{T}$ and $\bar{u}(x, 0)=0$ for all $x \in \bar{D}$. Now let $G$ be Green's function of the operator $\partial / \partial t-q_{1}\left(u_{1}\right)<1-f \Delta u_{2}$. Then, there holds

$$
\tilde{u}(x, t)=\int_{0}^{t} \int_{D} G(x, i, \xi ; \tau) \tilde{q}\left(u_{2}(\xi, \tau)\right) \Delta u_{2}(\xi, \tau) d \xi d \tau
$$

for all $(x, t) \in Z_{T}$. From this and (2.3) it follows that

$$
\int_{0}^{t} \int_{D} G\left(x^{0}, t, \xi, \tau\right) \tilde{q}\left(u_{2}(\xi, \tau)\right) \Delta \bar{u}_{2}(\xi, \tau) d \xi d \tau=0
$$

for all $t \in[0, T]$.

Since $\partial u_{2} / \partial t \geqq 0$ in $\bar{Z}_{T}, u_{2}(x, \cdot)$ is monotone increasing for fixed $x$. Thus $d=v_{0}$ with $v_{0}$ from (1.5). Further $\hat{q}$ is analytic in $\left[v_{0}{ }^{*}, v_{1}{ }^{*}\right]$. Hence we have: Either $\bar{q}=0$ on, $\left[v_{0}, v_{1}\right]$ or $q$ has at most finitely many zeros in $\left[v_{0}, v_{1}\right]$. We suppose the second case and denote by $z$ the least one of these zeros which is greater than $v_{0}$, if such a zero exists. If such a zero does not exist we set $z=v_{1}$. Thus we have $v_{0}<z$. Let $x^{1} \in \bar{D}$ with the property

$$
z \leqq \max \left\{u_{2}\left(x^{1}, t\right): 0 \leqq t \leqq T\right\}
$$

and $x^{2} \in \dot{\bar{D}}$ with the property

$$
z>\max \left\{u_{2}\left(x^{2}, t\right): 0 \leqq t \leqq T\right\} \text {. }
$$

Since for fixed $x \in \bar{D}$ the function $u_{2}(x, \cdot)$ is continuous and monotone increasing we obtain that for all $x=x^{1}$ with the property (2.5) there exists a $t(x)>0$ such that $u_{2}\left(x^{1}, \iota\left(x^{1}\right)\right)=z$. For all $x=x^{2}$ with the property $(2.6)$ we set $t\left(x^{2}\right)=T$. Then we have $v_{0} \leqq u_{2}(x, t) \leqq z$ for all $t \in[0, t(x)]$ and $x \in \bar{D}$. We put $J_{0}=\inf \{t(x): x \in \bar{D}\}$. Using the relations. $u_{2}\left(x^{1}, t\left(x^{1}\right)\right)=z$ and $t\left(x^{2}\right)=T$, the continuity of $u$ in $\bar{Z}_{7}$, the boundedness of $D$ and $v_{0}<z$ one can easily see that $T_{0}>0$.

From the assumption (2.1) it follows that $\left\langle u_{2}\left(x^{0}, t\right)>0\right.$ for all $t \in\left(0, t_{0}\right]$. Now we define $T_{0}^{*}=\min \left\{t_{0}, T_{0}\right\}$. Because of the continuity of $\Delta u_{2}$ there are a, neigh- 
borhood $S_{\varepsilon}\left(x^{0}\right)$ and an interval $\left(t_{1}, t_{2}\right) \leqq\left[0, T_{0}^{*}\right]$ such that

$$
\Delta u_{2}(x, t)>0 \text { for all }(x, t) \in B_{T_{0} *}=S_{c}\left(x^{0}\right) \times\left(t_{1}, t_{2}\right) .
$$

From the assumption (2.1) it follows also that

$$
u_{2}(x, t)>v_{0} \text { for all }(x, t) \in B_{T_{0} \bullet} \text {. }
$$

There holds either.

$$
\tilde{q}\left(u_{2}(x, t)\right) \geqq 0 \text { for all }(x, t) \in Z_{T_{0}} \text {. }
$$

or the inverse inequality. Let us assume (2.9). Then from (2.8) we obtain that

$$
\tilde{q}\left(u_{2}(x, t)\right)>0 \text { for all }(x, t) \in B_{T_{0}^{*}} \text {. }
$$

Since Green's function $G\left(x^{0}, T_{0}{ }^{*}, \xi, \tau\right)>0$ for all $(\xi, \tau) \in Z_{T_{0}}$ (compare A: FriedMAN [5]) we obtain from $(2.2),(2.7),(2.9),(2.10)$ that

$$
\int_{0}^{r_{0}^{*}} \int_{D} G\left(x^{0}, T_{0}^{*}, \xi, \tau\right) \tilde{q}\left(u_{2}(\xi, \tau)\right) \cdot \Delta u_{2}(\xi, \tau) d \xi d \tau>0 .
$$

But this is a contradiction to (2.4)

In Theorem $1,(2.2)$ is used as an additional condition on $u$. This condition means that $u(x, \cdot, q)$ is monotone increasing for fixed $x$ and $q$. In Section 4 we shall state conditions for $\varphi$ and $\psi$ which imply the relation (2.2).

\section{A uniqueness theorem for the case that $q$ is linear}

Now we assume that $q$ is a linear function of $u$. Then $q \in A$ and Theorem 1 can be applied. But in this case we can weaken the assumptions for the uniqueness of $q$. The linear function $q$. may be given in the form

$$
q(u)=b\left(u-v_{0}\right)+c \quad\left(u \in\left[v_{0}, v_{1}\right]\right),
$$

where $b$ and $c$ are real constants, with $c>0$ and $b>-c /\left(v_{1}-v_{0}\right)$. This implies $q(u)>0$ for all $u \in\left[v_{0}, v_{1}\right]$.

Further we assume that $c=q\left(v_{0}\right)$ is known. Then $q(u)$ is completely known if the constant $b$ ist known. Thus now we write $u(x, t, b)$ instead of $u(x, t, q)$. We obtain that in this case $q$ is uniquely determined if only $u\left(x^{0}, t_{0}, q\right)=g^{*}$ is known for a fixed point $\left(x^{0}, i_{0}\right) \in Z_{T}$.

Theorem 2: Let $p$ and $\psi$ be given functions satisfying (1.4). Let the function u satisfy (1.6) and the condition

$$
u_{t}(x, t, b) \geqq 0 \text { for all }(x, t) \in Z_{T}^{\prime} \text { and all } b \text {. }
$$

Finally, let $\left(x^{0}, t_{0}\right) \in Z_{T}$, and let $g^{*}$ be a real number with $\varphi\left(x^{0}\right) \neq g^{*}$. Then there is at most one number $b .>-c /\left(v_{1}-v_{0}\right)$ such that $u\left(x^{0}, t_{0}, b\right)=g^{*}$.

Proof: let $b_{1}, b_{2}$ be two numbers with $b_{i}>-c /\left(v_{1}-v_{0}\right)(i=1,2)$ and,

$$
\text { . } \quad u\left(x^{0}, t_{0}, b_{1}\right)=u\left(x^{0}, t_{0}, b_{2}\right)=g^{*} \text {. }
$$


For abbreviation we set $u_{i}(x, t)=u\left(x, t, b_{i}\right)(i=1,2), \bar{u}=u_{1}-u_{2}, \bar{q}=q_{1}-q_{2}$. Then $u$ satisfies the differential equation

$$
\frac{\partial \bar{u}}{\partial t}-\left(b_{1}\left(u_{1}-v_{0}\right)+c\right) \Delta \bar{u}-b_{1} \Delta u_{2} \bar{u}=\left(b_{1}-b_{2}\right)\left(u_{2}-v_{1}\right) \Delta u_{2}
$$

with homogeneous initial and boundary condition. Now let $G$ be Green's function of the operator $\partial / \partial t-\left(b_{1}\left(u_{1}-v_{0}\right)+c\right) \Delta-b_{1} \Delta u_{1}$. Then there holds

$$
\tilde{u}(x, t)=\int_{0}^{l} \int_{D} G(x, l, \xi, \tau)\left(u_{2}(\xi, \tau)-v_{0}\right) \Delta u_{2}(\xi, \tau) d \xi d \tau\left(b_{1}-b_{2}\right)
$$

for all $(x, t) \in Z_{T}$. From this and (3.2) it. follows that

$$
\int_{0}^{t_{0}} \int_{D} G\left(x^{0}, t_{0}, \xi, \tau\right)\left(\iota_{2}(\xi, \tau)-v_{0}\right) \Delta \iota_{2}(\xi, \tau) d \xi d \tau\left(b_{1}-b_{2}\right)=0 .
$$

We have $G\left(x^{0}, t_{0}, \xi, \tau\right)>0$ for all $(\xi, \tau) \in Z_{t_{0}}$. Using $\varphi\left(x^{0}\right) \neq g^{*},(3.1)$ and (3.2) and the continuity of $u_{2}\left(x^{0}, \cdot\right)$ on $\left[0, t_{0}^{0}\right]$ we obtain that there exists a $t_{1} \in\left(0, t_{0}\right)$ such that $u_{2}\left(x^{0}, t_{1}\right)>v_{0}$ and $\Delta u_{2}\left(x^{0}, t_{1}\right)>0$. Thus by the continuity of $u_{2}(x, t)$ and $\Delta u_{2}(x, t)$ it follows that the integral on the left hand side of $(3.3)$ is unequal to zero. Hence $b_{1}=b_{2}$

\section{Conditions for the monotonicity of $u$ as a function of $t$}

In both theorems of this paper we have used the supposition $\partial u(x, t) / \partial t \geqq 0$ for all $(x, t) \in Z_{T}$. In the following proposition we shall state conditions for $\varphi$ and $\psi$ whicli imply this relation.

Proposition: Let $\varphi, \psi$ be given functions which, salisfy the condition (1.4). Let $q \in A$, and let $u$ be a solution of the boundury value problem (1.3) satisfying condition (1.6). In addition we assume that for every fixed $x \in \partial D$ the function $\psi(x ;:)$ is continuously differentiable on $[0, T]$ with $\dot{\psi}_{t}(x, 0)=0$ and $\psi_{t}(x, \cdot) \geqq 0$, and $\varphi$ is a constant function. Then we have $\partial u(x, t) / \partial t \geqq 0$ for all $(x, t) \in \bar{Z}_{T}$.

Proof: From (1.6) and (1.3) there follows that $u_{t}(x, t) \in C\left(\bar{Z}_{r}\right)$. lett $w=u_{t}$. Then there holds

$$
\begin{aligned}
& w_{t}(x, t)=q(u(x, t)) \Delta u(x, t)+q^{\prime}(u(x, t)) \Delta u(x, t) w(x, t) \quad \text { in } Z_{T}, \\
& w(x, t)=\psi_{t}(x, t) \text { on } \Gamma_{T}, \quad w(x, 0)=0 \text { in } \bar{D} .
\end{aligned}
$$

$q^{\prime}(u)$ and $\Delta u$ are bounded in $Z_{T}$. On the boundary $\dot{I}_{T} \cup \bar{D}$ we have $w(x, t) \geqq 0$. Using a mininum principle (comp. A. M. IL'IN, A. S. KaLASHNIKov and O. A. OLEINIK [6: p. 8]) we obtain $u_{t}(x, t)=w(x, t) \geqq 0$ for all $(x, t) \in \bar{Z}_{T}$

\section{REFERENCES}

[1] Безноценго; Н. Я.: Об определении коеффициентон при старйнх пропзводиых в параболическом уравиенин. Дифф. ур-ия 11 (1975), 19-26.

[2] Бухгелм, А. Л., и М. В. Кливанов: Единственность в целом одного класса многомерных обратных задач. Докл. Акад. Наук СССР 260 (1981), $269-272$.

[3] Duchatedu, P.: Monotonicity and uniqueness results identifying an unkiown coefficient in a nonlincar diffusion equation. SIAM J. Appl. MLuth. 41 (1981). 310-323. 
[4] Dümmei, S.: On some inverse problems for partial differential equations. In: Proc: Equadiff IV Prague 1977 (Lecture Notes in Matheniatics 703). Berlin-Heidelberg - New York: Springer-Verlag 1979, 93-98.

[5] Friednan, A.: Pàrtial differential equations of parabolic type. Englewood Cliffs NJ: Prentice Hall 1964.

[6] Ильин, А. М., КАлашников, А. С., п О. А. ОлЕйник: Линейные уравнения второго порядка параболического типа. Успехи Мат. Наук 17 (1962), вуп. 3 (105), 3-146.

[7] ИСАков, В.М:: Об одном классе об̆ратных задач для параболических уравнсний. Докл. Акац. Наук СССР 263 (1982), 1296-1299.

[8] Искендеров, А. Д.: Многомерные обрратные задачи цля линейных и квазилинейных параболических уравнений. Докіл. А́кад. Наук СССР 225 $(1975), 1005-1008$.

[9] Музылёв, Н: В.: Теоремы единственности для некоторых обратных задач теплопроводности. Ж Курн. Вычисл. Мат. и Мат. Физ. 20 (1980), 388-400.

[10] Pagani, C. D. $\vdots$ Determining a coefficient in a parabolic equation. Appl. Anal. 14 (1982), $99-116$.

Manuskriptẹingang: 23.07. 1984

\section{VERFASSER :}

Prof. Dr. Siegraied Dü MMel

Sektion Mathematik der Technischen Hochschule

DDR-9010 Karl-Marx-Stadt, Reichenhainer Str. 39-41 